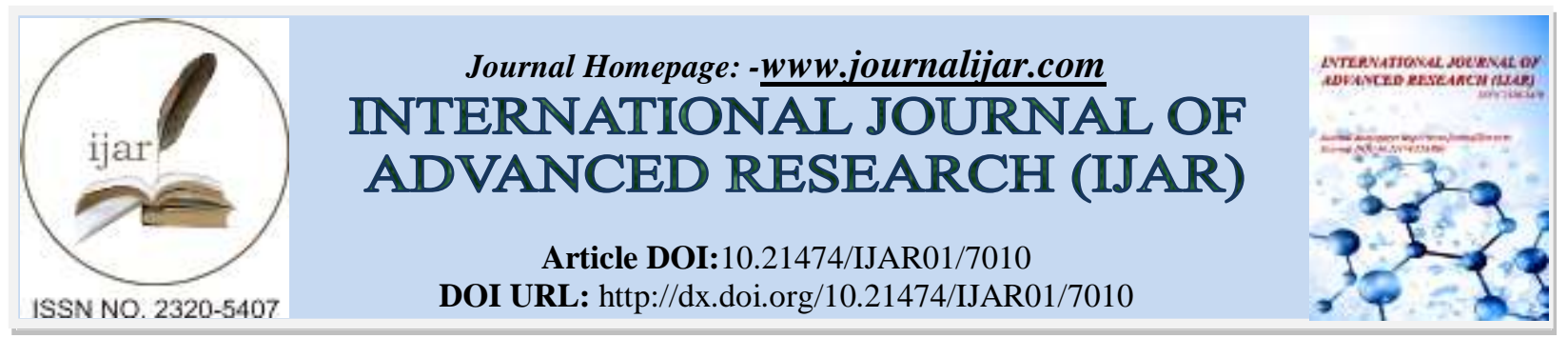

RESEARCH ARTICLE

\title{
THEORETICAL STUDIES OF ELECTRONIC AND OPTICAL PROPERTIES FOR SOME NEW AZO DISPERSE DYES FOR DYE-SENSITIZED SOLAR CELLS BY USING TD AND TD DFT METHOD.
}

\author{
Isaac Onoka, Numbury Surendra Babu and John J. Makangara. \\ Department of Chemistry, College of Natural and Mathematical Sciences,The University of Dodoma, post box: 338, \\ Dodoma, Tanzania.
}

\section{Manuscript Info}

Manuscript History

Received: 01 March 2018

Final Accepted: 03 April 2018

Published: May 2018

Keywords:-

Azo disperse dyes; DFT; TD-DFT;

Electronic properties; Photovoltaic properties.

\begin{abstract}
The ground states geometries, absorption wavelengths, oscillation strengths of new azo disperse dyes such as 3-aminopyrazoleazo -4thiol-2,3,5-thiadiazole (D1),3-amino-4-methylpyrazoleazo-4-thiol-2,3, 5-thiadiazol (D2),2, 4-dihydroxybenzeneazo-4-thiol 1-2, 3,5thiadiazole (D3),4-amino-3-benzonitrileazo-4-thiol-2,3,5-thiadiazole (D4), 2-hydroxylnaphtholazo-4-thiol-2,3,5-thiadiazole (D5) and 2amino-5-ethylcarbazoleazo-4-thiol-2,3,5-Thiadiazole (D6) have been optimized by using density functional theory (DFT) at B3LYP level of theory with $6-31 \mathrm{G}(\mathrm{d})$ basis set. The excitation energies have been computed by using time dependent density functional theory (TDDFT). The study of structural, electronic and optical properties for these dyes could help to design more efficient functional photovoltaic organic materials. The electron injection $\left(\Delta \mathrm{G}_{\text {inject }}\right)$, electron coupling constants (|VRP|) and light harvesting efficiencies (LHE) of studied dyes and have been discussed with esteem to DSSCs. This theoretical designing will the pave way for experimentalists to synthesize the efficient sensitizers for solar cells.
\end{abstract}

Copy Right, IJAR, 2018,. All rights reserved.

\section{Introduction:-}

Research in renewable energy has become one of the most imperative issues in global energy strategy due to increased energy consumption and limited fossil resources. The incident solar energy on earth per hour exceeds the current consumption of the energy of the world per year. The necessity of cultivating renewable energy sources is growing day by day [1]. Therefore, efficient solar energy conversion provides a promising technology for balancing the increasing energy demand due to fast industrial development [2]. New photovoltaic (PV) energy technologies can contribute to environmentally friendly, renewable energy production, and the reduction of the carbon dioxide emission associated with fossil fuels and biomass.

One new PV technology, organic solar cell technology, is based on conjugated polymers and molecules. Organic solar cells are a type of polymer solar cells which use conductive organic polymers or small organic molecules for light absorption and charge transport to produce electricity from sunlight by the photovoltaic effect. Organic solar cells have attracted considerable attention in the past few years owing to their potential of providing environmentally safe, flexible, lightweight, inexpensive and efficient solar cells. Among all the renewable energy technologies, the nanocrystalline dye-sensitized solar cell (DSSC) system, a kind of photovoltaic device that 
presented by O'Regan and Gratzel in 1991, has attracted a lot of attention because of the potential application for low-cost solar electricity [3-6].

DSSCs are solar cells, belonging to third generation of solar cells; they are based on Nature's principles of photosynthesis. DSSCs are composed of a porous layer of titanium dioxide nanoparticles, covered with a molecular dye that absorbs sun light very similar to the chlorophyll in green leaves. The titanium dioxide is immersed under an electrolyte solution, above which is a platinum-based catalyst which acts as a counter electrode. This chemical way of assembling the cell architecture allows facile and cost effective processing which makes these cells front runners in the view of the basic design novelty and potential for low cost manufacturing.

The efficiency of DSSC is the bottleneck of the design and test of the new materials (e.g. dye sensitizer) for DSSCs, which have been dominated by the often costly and time-consuming synthesis procedures [7]. As in the case of new dye sensitizer materials development, it is difficult for synthetic chemists to work out high-performance dyes with the desirable properties prior to the experiments on the assembled cell, without any support on the information of the new dyes [8]. In some cases, disappointing results from the most late-stage of the dye synthesis laboratories indicate an urgent need to understand the physical origin of dyes at molecular level, prior to experiments taking place. To overcome this bottleneck in the development of new DCCSs with better efficiency, the state-of-art computational methods need to be utilized. Today, accurate first-principle quantum chemical calculations are made available on supercomputing facilities accessible to more research groups. Such calculations are a reliable tool to design, study, and screen new materials prior to synthesis. Computer-aided rational design of new dye sensitizers based on the systematic chemical modifications of the dye structure has recently drawn the attention of several groups, including ours [9-17].

Further developments in dye design will play a crucial part in the ongoing optimization of DSSC [36], and it depends on the quantitative knowledge of dye sensitizer. So the theoretical investigations of the physical properties of dye sensitizers are very important in order to disclose the relationship among the performance, structures and the properties, it is also helpful to design and synthesis novel dye sensitizers with higher performance.

Azo compounds are a very important class of chemical compounds receiving attention in scientific research. They are highly colored and have been used as dyes and pigments for a long time [18-20]. Furthermore, they have been studied widely because of their excellent thermal and optical properties in applications such as optical recording medium [21-24], toner [25], ink-jet printing [26], and oil-soluble lightfast dyes [27].A survey of the literature reveals that the intermediate for this study, 2-amino-1, 3, 4-thiadiazole-2-thiol has recently been used to synthesize two organic dyes and their metal complexes, using carbocyclic coupling components

\section{Computational Methods:-}

The computations of the ground state geometries, electronic structures, and electronic absorption spectrum for studied dye sensitizers were done using DFT with Gaussian 09 package [28] with Becke's three parameter gradientcorrected exchange potential and the Lee-Yang-Parr gradient-corrected correlation potential (B3LYP) [29-31], and all calculations were performed without any symmetry constraints by using polarized split-valence 6-31G(d) basis set. The electronic absorption spectrum requires calculation of the allowed excitations and oscillator strengths. The HOMO, LUMO and gap (HOMO-LUMO) energies are also deduced for the stable structures. Therefore, the ground state energies and oscillator strengths were investigated using TD-DFT calculations on the entirely DFT optimized geometries. The vertical excitation energy and electronic absorption spectra were simulated using TD-DFT with B3LYP/6-31G (d) level ingas phase. The power conversion efficiency of each molecule was determined by the position of the band gap depending on the difference [LUMO (molecule) - LUMO (acceptor)]. In this research paper to attempt has been made to characterize new azo dyes.

These dyes were synthesized from 2-amino-1,3,4-thiadiazole-2-thiol [32]. The studied dye molecules are 3Aminopyrazoleazo -4-thiol-2,3,5-thiadiazole (D1),3-Amino-4-methylpyrazoleazo-4-thiol-2,3, 5-Thiadiazol (D2),2, 4-Dihydroxybenzeneazo-4-thiol 1-2, 3,5-thiadiazole (D3),4-Amino-3-benzonitrileazo-4-thiol-2,3,5-thiadiazole (D4),2-Hydroxylnaphtholazo-4-thiol-2,3,5-thiadiazole (D5) and 2-Amino-5-ethylcarbazoleazo-4-thiol-2,3,5Thiadiazole (D6).

In the present research work, to make an effort to determine and evaluate the geometrical parameters, the absorption peaks $\left(\lambda_{\max }\right)$ in the UV spectra of thestudied dyes. In addition to analyze electro- optical properties, electron 
injection, electronic copling constants, light harvesting efficiencies, open circuit voltages $\left(\mathrm{V}_{\mathrm{oc}}\right)$ and Quantum chemical parameters.

\section{Results And Discussion:-}

Ground state geometry:-

The optimized structures of all studied dyes are shown in figure 1. All the molecular geometries have been calculated by DFT with the hybrid B3LYP functional theory combined with 6-31G (d) basis sets using Gaussian 09 program. The selected bond lengths, bond angles and dihedral angles are presented in Table 1. From the results, we find that the addition of donor groups induce a slight change in the dihedral torsion angles and bond lengths. A slight decrease in the $\mathrm{N}=\mathrm{N}$ double bond lengths (D3, D4 and D5) with comparison of D1 and slight increase in D6 as the following order: D6 > D2 > D1 > D5 > D3 > D4), because due to the different electron donor groups added. On the other hand, the twisting of the chain backbone is investigated by the dihedral angle's variety as indicated in table 1; we found that the dihedral angles are similar for all compounds $\left(\sim 180^{\circ}\right.$ or $\left.0^{\circ}\right)$ due to aromatic rings are attached to the thiadiazole cycles, which give an almost flat structure for these studied compounds.

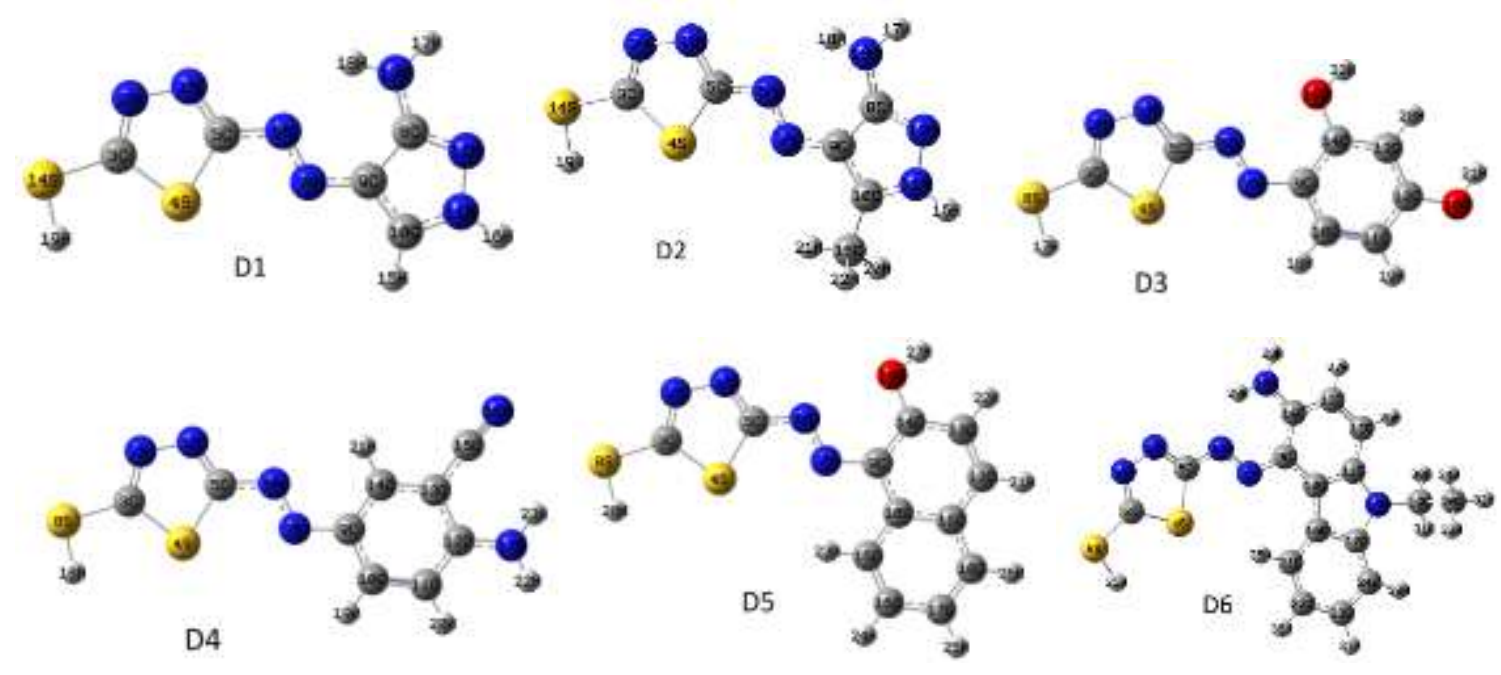

Figure1:-Optimized geometries obtained by DFT/B3LYP with 6-31G (d) basis set in gas phase.

\section{Electronic properties:-}

Electronic properties of the HOMO and LUMO energy levels of the dyes are crucial in studying organic solar cells. The HOMO and LUMO energy levels of the donor and of the acceptor dyes for photovoltaic devices are key important factors to determine whether the effective charge transfer will happen between donor and acceptor.The HOMO and LUMO energies of the studied dyes are computed in Table 2 and Figure 2 shows the frontier molecular orbitals for all the six dyes. From the results (Table.2) the highest occupied and lowest unoccupied molecular orbital's get approximate HOMO /LUMO energies of -5.8766/-2.5919 eV for D1, -5.8053/-2.5045eV for D2, 5.9933/-2.5840 eV for D3, -6.1169/-2.9465 eV for D4, -5.8529/ -2.7835 eV for D5 and -5.1266/ -2.6248 eV for D6, corresponding to energy gaps of $3.2847 \mathrm{eV}$ for D1, $3.3007 \mathrm{eV}$ for D2, $3.4093 \mathrm{eV}$ for D3, $3.1704 \mathrm{eV}$ for D4, 3.0694 $\mathrm{eV}$ for D5 and $2.5078 \mathrm{eV}$ for D6. The lower energy gap $\left(\mathrm{E}_{\mathrm{g}}\right)$ of D6, D5 and D4 compared to that of D1 shows a significant effect of intra molecular charge transfer, which would make the absorption spectra to red shifted.

This is due to the effect of the electron-donor unit which is strong of D6, D5, and D4 than that of other dyes and these molecules expected to have the most outstanding photophysical properties especially D6.The injection of electron from dye to semiconductor is depends on the HOMO and the LUMO energy levels of the dye (donor) and semiconductor (acceptor). For effective injection of the electron from the excited dye into the acceptor (metal oxide semiconductor e.g. $\mathrm{TiO}_{2}$,) the LUMO level of the dye needs to be higher than the conduction band edge of the acceptor. The band edge of $\mathrm{TiO}_{2}$ is approximately at $-4.2 \mathrm{eV}$ (relative to vacuum) and the LUMO energy level of D1, D2, D3, D4, D5, and D6 were -2.5919 eV, -2.5045eV, -2.5840 eV, -2.9465 $\mathrm{eV}$ respectively, indicating that the LUMO levels of all four dyes are higher than the conduction band edge of $\mathrm{TiO}_{2}$. 
Table 1:-Optimized selected bond length in angstroms $\left(\mathrm{A}^{0}\right)$, bond angles and dihedral angles in degree $\left({ }^{0}\right)$ of the studied dyes obtainedby DFT/B3LYP with 6-31G (d) basis set in gas phase.

\begin{tabular}{|c|c|c|c|c|c|c|c|c|c|c|c|}
\hline \multicolumn{12}{|c|}{ Bond length $\left(\mathbf{A}^{0}\right)$} \\
\hline \multicolumn{2}{|c|}{ D1 } & \multicolumn{2}{|c|}{ D2 } & \multicolumn{2}{|c|}{ D3 } & \multicolumn{2}{|c|}{ D4 } & \multicolumn{2}{|c|}{ D5 } & \multicolumn{2}{|c|}{ D6 } \\
\hline bond & length & bond & length & bond & length & bond & length & bond & length & bond & length \\
\hline N1-N2 & 1.3614 & N1-N2 & 1.3621 & N1-N2 & 1.3602 & N1-N2 & 1.3574 & N1-N2 & 1.3588 & N1-N2 & 1.3614 \\
\hline N1-C5 & 1.3067 & N1-C5 & 1.3067 & N1-C5 & 1.3060 & N1-C5 & 1.3075 & N1-C5 & 1.3071 & N1-C5 & 1.3090 \\
\hline N2-C3 & 1.3066 & N2-C3 & 1.3057 & N2-C3 & 1.3086 & N2-C3 & 1.3098 & N2-C3 & 1.3090 & N2-C3 & 1.3057 \\
\hline C3-S4 & 1.7554 & C3-S4 & 1.7560 & C3-S4 & 1.7520 & C3-S4 & 1.7523 & C3-S4 & 1.7518 & C3-S4 & 1.7560 \\
\hline C3-S14 & 1.7656 & C3-S14 & 1.7663 & C3-S8 & 1.7652 & C3-S8 & 1.7632 & C3-S8 & 1.7645 & C3-S8 & 1.7665 \\
\hline S4-C5 & 1.7825 & S4-C5 & 1.7842 & S4-C5 & 1.7873 & S4-C5 & 1.7832 & S4-C5 & 1.7882 & S4-C5 & 1.7833 \\
\hline C5-N6 & 1.3767 & C5-N6 & 1.3760 & C5-N6 & 1.3800 & C5-N6 & 1.3777 & C5-N6 & 1.3777 & C5-N6 & 1.3714 \\
\hline N6-N7 & 1.2807 & N6-N7 & 1.2820 & N6-N7 & 1.2702 & N6-N7 & 1.2693 & N6-N7 & 1.2716 & N6-N7 & 1.2864 \\
\hline N7-C9 & 1.3629 & N7-C9 & 1.3591 & N7-C9 & 1.3906 & N7-C9 & 1.3976 & N7-C9 & 1.3886 & N7-C9 & 1.3703 \\
\hline S14-H19 & 1.3489 & S14-H19 & 1.3489 & S8-17 & 1.3489 & S8-H18 & 1.3490 & S8-H20 & 1.3488 & S8-25 & 1.3489 \\
\hline \multicolumn{12}{|c|}{ Bond Angles } \\
\hline \multicolumn{2}{|l|}{ D1 } & \multicolumn{2}{|l|}{ D2 } & \multicolumn{2}{|l|}{ D3 } & \multicolumn{2}{|l|}{ D4 } & \multicolumn{2}{|c|}{ D5 } & \multicolumn{2}{|c|}{ D6 } \\
\hline bond & $\mathrm{A}^{0}$ & bond & $\mathrm{A}^{0}$ & bond & $\mathrm{A}^{0}$ & bond & $\mathrm{A}^{0}$ & bond & $\mathrm{A}^{0}$ & bond & $\mathrm{A}^{0}$ \\
\hline $\mathrm{N} 2, \mathrm{~N} 1, \mathrm{C} 5$ & 113.3 & $\mathrm{~N} 2, \mathrm{~N} 1, \mathrm{C} 5$ & 113.3 & $\mathrm{~N} 2, \mathrm{~N} 1, \mathrm{C} 5$ & 113.3 & $\mathrm{~N} 2, \mathrm{~N} 1, \mathrm{C} 5$ & 113.2 & $\mathrm{~N} 2, \mathrm{~N} 1, \mathrm{C} 5$ & 113.4 & $\mathrm{~N} 2, \mathrm{~N} 1, \mathrm{C} 5$ & 113.2 \\
\hline $\mathrm{N} 1, \mathrm{~N} 2, \mathrm{C} 3$ & 112.9 & $\mathrm{~N} 1, \mathrm{~N} 2, \mathrm{C} 3$ & 112.9 & $\mathrm{~N} 1, \mathrm{~N} 2, \mathrm{C} 3$ & 112.7 & $\mathrm{~N} 1, \mathrm{~N} 2, \mathrm{C} 3$ & 112.8 & $\mathrm{~N} 1, \mathrm{~N} 2, \mathrm{C} 3$ & 112.8 & $\mathrm{~N} 1, \mathrm{~N} 2, \mathrm{C} 3$ & 112.9 \\
\hline $\mathrm{N} 2, \mathrm{C} 3, \mathrm{~S} 4$ & 115.1 & $\mathrm{~N} 2, \mathrm{C} 3, \mathrm{~S} 4$ & 115.1 & $\mathrm{~N} 2,3, \mathrm{~S} 4$ & 115.3 & $\mathrm{~N} 2, \mathrm{C} 3, \mathrm{~S} 4$ & 115.1 & $\mathrm{~N} 2, \mathrm{C} 3, \mathrm{~S} 4$ & 115.2 & $\mathrm{~N} 2, \mathrm{C} 3, \mathrm{~S} 4$ & 115.0 \\
\hline $\mathrm{N} 2, \mathrm{C} 3, \mathrm{~S} 14$ & 119.6 & $\mathrm{~N} 2, \mathrm{C} 3, \mathrm{~S} 14$ & 119.6 & $\mathrm{~N} 2, \mathrm{C} 3, \mathrm{C} 8$ & 119.3 & $\mathrm{~N} 2, \mathrm{C} 3, \mathrm{~S} 14$ & 119.5 & $\mathrm{~N} 2, \mathrm{C} 3, \mathrm{~S} 8$ & 119.3 & $\mathrm{~N} 2, \mathrm{C} 3, \mathrm{~S} 8$ & 119.7 \\
\hline $\mathrm{S} 4, \mathrm{C} 3, \mathrm{~S} 14$ & 125.1 & S4,C3,S14 & 125.1 & $\mathrm{~S} 4, \mathrm{C} 3, \mathrm{C} 8$ & 125.3 & $\mathrm{~S} 4, \mathrm{C} 3, \mathrm{~S} 14$ & 125.2 & $\mathrm{~S} 4, \mathrm{C} 3, \mathrm{~S} 8$ & 125.3 & $\mathrm{~S} 4, \mathrm{C} 3, \mathrm{~S} 8$ & 125.1 \\
\hline $\mathrm{C} 3, \mathrm{~S} 4, \mathrm{C} 5$ & 84.8 & $\mathrm{C} 3, \mathrm{~S} 4, \mathrm{C} 5$ & 84.8 & $\mathrm{C} 3, \mathrm{~S} 4, \mathrm{C} 5$ & 84.7 & $\mathrm{C} 3, \mathrm{~S} 4, \mathrm{C} 5$ & 84.7 & $\mathrm{C} 3, \mathrm{~S} 4,5$ & 84.7 & $\mathrm{C} 3, \mathrm{~S} 4, \mathrm{C} 5$ & 84.8 \\
\hline N1,C5,S4 & 113.8 & $\mathrm{~N} 1, \mathrm{C} 5, \mathrm{~S} 4$ & 113.8 & $\mathrm{~N} 1, \mathrm{C} 5, \mathrm{~S} 4$ & 113.8 & $\mathrm{~N} 1, \mathrm{C} 5, \mathrm{~S} 4$ & 113.9 & $\mathrm{~N} 1, \mathrm{C} 5, \mathrm{~S} 4$ & 113.7 & $\mathrm{~N} 1, \mathrm{C} 5, \mathrm{~S} 4$ & 113.7 \\
\hline N1,C5,N6 & 121.9 & $\mathrm{~N} 1, \mathrm{C} 5, \mathrm{~N} 6$ & 121.9 & $\mathrm{~N} 1, \mathrm{C} 5, \mathrm{~N} 6$ & 122.2 & N1,C5,N6 & 121.9 & $\mathrm{~N} 1, \mathrm{C} 5, \mathrm{~N} 6$ & 122.0 & $\mathrm{~N} 1, \mathrm{C} 5, \mathrm{~N} 6$ & 121.8 \\
\hline S4,C5,N6 & 124.1 & S4,C5,N6 & 124.1 & S4,C5,N6 & 123.9 & S4,C5,N6 & 124.1 & S4,C5,N6 & 124.2 & S4,C5,N6 & 124.3 \\
\hline C5,N6,N7 & 113.6 & $\mathrm{C} 5, \mathrm{~N} 6, \mathrm{~N} 7$ & 113.6 & C5,N6,N7 & 112.4 & C5,N6,N7 & 113.5 & C5,N6,N7 & 112.8 & C5,N6,N7 & 114.3 \\
\hline N6,N7,C9 & 115.5 & N6,N7,C9 & 115.5 & N6,N7,C9 & 118.5 & N6,N7,C9 & 115.0 & N6,N7,9 & 118.6 & $\mathrm{N6,N7,C9}$ & 118.1 \\
\hline $\mathrm{C} 3, \mathrm{~S} 14, \mathrm{H} 19$ & 96.0 & $\mathrm{C} 3, \mathrm{~S} 14, \mathrm{H} 19$ & 96.0 & $\mathrm{C} 3, \mathrm{~S} 8, \mathrm{H} 17$ & 96.0 & $\mathrm{C} 3, \mathrm{~S} 14, \mathrm{H} 19$ & 96.0 & $\mathrm{C} 3, \mathrm{~S} 8,20$ & 96.0 & $\mathrm{C} 3, \mathrm{~S} 8, \mathrm{H} 25$ & 96.0 \\
\hline $\mathrm{N} 7, \mathrm{C} 9, \mathrm{C} 8$ & 131.4 & $\mathrm{~N} 7, \mathrm{C} 9, \mathrm{C} 8$ & 131.4 & $\mathrm{~N} 7, \mathrm{C} 9, \mathrm{C} 10$ & 113.9 & $\mathrm{~N} 7, \mathrm{C} 9, \mathrm{C} 8$ & 131.3 & $\mathrm{~N} 7, \mathrm{C} 9, \mathrm{C} 10$ & 114.8 & $\mathrm{N7,C9,C10}$ & 116.2 \\
\hline $\mathrm{N} 7, \mathrm{C} 9, \mathrm{C} 10$ & 123.5 & $\mathrm{~N} 7, \mathrm{C} 9, \mathrm{C} 10$ & 123.5 & $\mathrm{~N} 7, \mathrm{C} 9, \mathrm{~S} 14$ & 128.1 & $\mathrm{~N} 7, \mathrm{C} 9, \mathrm{C} 10$ & 124.2 & $\mathrm{~N} 7, \mathrm{C} 9, \mathrm{C} 14$ & 126.3 & N7,9C,C14 & 125.7 \\
\hline
\end{tabular}

\begin{tabular}{|c|c|c|c|c|c|c|c|}
\hline \multicolumn{9}{|c|}{ D1 } & D2 & DIHYDAL & D3 & D4 & D5 & D6 \\
\hline DIHYDAL & -179.2115 & -179.0600 & N1,C5,N6,N7 & -179.9884 & 179.9687 & 179.9870 & -179.9502 \\
\hline N1,C5,N6,N7 & 0.8042 & 0.9776 & S4,C5,N6,N7 & 0.0083 & -0.0697 & -0.0039 & 0.0189 \\
\hline S4,C5,N6,N7 & -177.9276 & -177.9217 & N6,N7,C9,C10 & 179.9930 & -179.9876 & 179.9954 & 179.8673 \\
\hline N6,N7,C9,C10 & -0.6037 & 0.2098 & N6,N7,C9,C14 & 0.0015 & 0.0317 & -0.0075 & 0.0763 \\
\hline N6,N7,C9,C8 & &
\end{tabular}

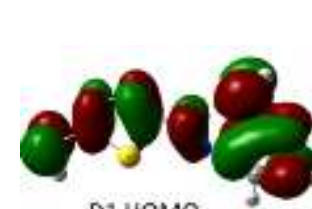

D1 HOMO

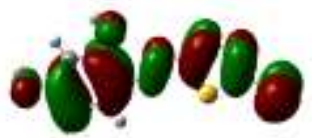

D3 HOMO

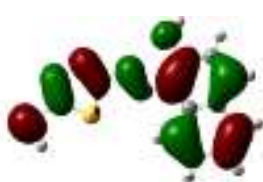

D5 HOMO

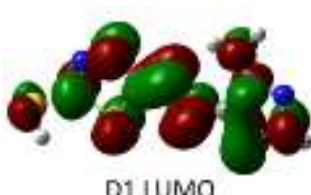

D1 LUMO
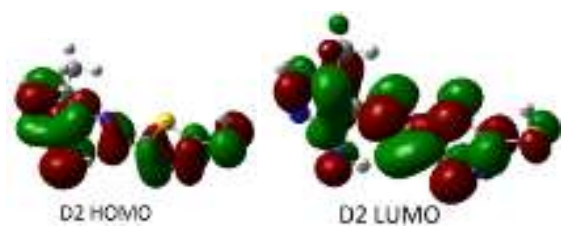

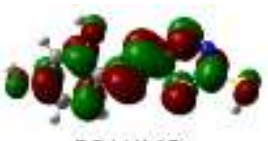

D3 LUMO

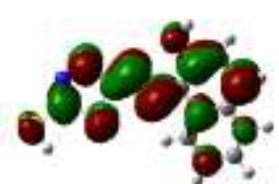

DS LUMO

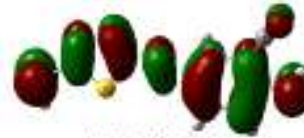

DA HOMO

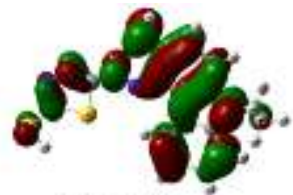

D6 HOMO
D2 LUMO

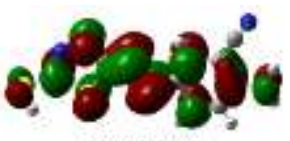

D4 LUMO

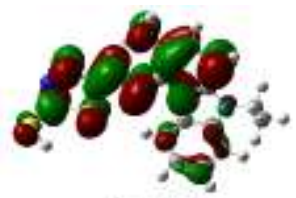

D6 LUMO

Figure 2:-The contour plots of HOMO and LUMO orbitals of the studied dyes by DFT/B3LYP with 6-31G(d) basis set in gas phase. 
Table 2:-Calculated $\mathrm{E}_{\text {номо, }} \mathrm{E}_{\mathrm{LUMO}}$ levels, energy gap (Eg), dipole moment $(\rho)$ and other quantum parameters chemical as chemical potential $(\mu)$, chemical hardness $(\eta)$, electronegativity $(\chi)$, and electrophilicity $(\omega)$ values of the studied compounds obtained by B3LYP/6-31G(d) level in gas phase.

\begin{tabular}{|c|c|c|c|c|c|c|c|c|}
\hline dyes & HOMO(ev) & LUMO(ev) & $\mathrm{E}_{\mathrm{g}}(\mathrm{ev})$ & $\mu(\mathrm{ev})$ & $\eta(\mathrm{ev})$ & $\chi(\mathrm{ev})$ & $\omega(\mathrm{ev})$ & $\rho(\mathrm{debye})$ \\
\hline D1 & -5.8766 & -2.5919 & 3.2847 & -4.2343 & 1.6424 & 4.2343 & 5.45830 & 6.1942 \\
\hline D2 & -5.8053 & -2.5045 & 3.3007 & -4.1549 & 1.6504 & 4.1549 & 5.23000 & 6.7855 \\
\hline D3 & -5.9933 & -2.5840 & 3.4093 & -4.2887 & 1.7047 & 4.2887 & 5.39481 & 6.6111 \\
\hline D4 & -6.1169 & -2.9465 & 3.1704 & -4.5317 & 1.5852 & 4.5317 & 6.47751 & 8.7196 \\
\hline D5 & -5.8529 & -2.7835 & 3.0694 & -4.3182 & 1.5347 & 4.3182 & 6.07508 & 6.4283 \\
\hline D6 & -5.1266 & -2.6248 & 2.5018 & -3.8757 & 1.2509 & 3.8757 & 6.00410 & 7.3898 \\
\hline
\end{tabular}

The HOMO level of the dye needs to be sufficiently lower than the redox couple to ensure the efficient regeneration of the dye. The most widely used redox couple in the electrolyte of DSSC is the $\mathrm{I}^{-} / \mathrm{I}^{-3}$ pairs where the estimated energy level is at $-4.8 \mathrm{eV}$ (relative to vacuum). The HOMO of $-5.8766 \mathrm{eV}$ for D1, $-5.8053 \mathrm{eV}$ for D2, $-5.9933 \mathrm{eV}$ for $\mathrm{D} 3,-6.1169 \mathrm{eV}$ for $\mathrm{D} 4,-5.8529 \mathrm{eV}$ for $\mathrm{D} 5$ and $-5.1266 \mathrm{eV}$ for $\mathrm{D} 6$, which are more negative than the energy level of the redox couple.

\section{Quantum chemical parameters:-}

Quantum chemical parameters such as hardness $(\eta)$, chemical potential $(\mu)$, electrophilicity index $(\omega)$ and electron negativity $(\chi)$ have been calculated from HOMO and LUMO energies [33-36] based on Koopman's theory from density functional theory calculation and the values are listed in Table 2 for studied dyes.

$$
\begin{gathered}
\mu=\left(E_{\text {Hомо }}+E_{\text {LUMO }}\right) / 2 \\
\eta=\left(E_{\text {LUMO }}-E_{\text {HOMO }}\right) / 2 \\
\chi=-\left(E_{\text {HOMO }}+E_{\text {LUMO }}\right) / 2 \\
\omega=\frac{\mu^{2}}{2 \eta}
\end{gathered}
$$

From the table 2, we note that the D6 has the highest value of the chemical potential $(\mu=-3.8 \mathrm{eV})$ compared to other dyes (D1, D2, D3, D4, and D5), this is a tendency to view the electrons to escape from D6 easily. Therefore D6 behaves as good donor of electrons comparison of others dyes. For the electronegativity, the D6 has a low value of electronegativity than other compounds (D1, D2, D3, D4, and D5) (Table 2), thus the D6 is the dye that is able to donate to him the electrons from others compounds (semiconductor). In another hand, the D6 dye has a low value of chemical hardness $(\eta)$ in comparison with other dyes; this indicates that the D6 is very easy to liberate the electrons. The order of liberate of the electrons are D6> D5> D4> D1> D2 >D3.

Electrophilicity index $(\omega)$ is a measure of energy lowering due to maximal electron flow between donor and acceptor [37]. This index measures the propensity of chemical species to accept electrons. A good, more reactive, nucleophile is characterized by lower value of $\omega$, and conversely a good electrophile is characterized by a high value of $\omega$. Therefore the D6 dye is a good electron donating molecule. Generally, the molecules having a large dipole moment, possesses a strong asymmetry in the distribution of electronic charge, therefore can be more reactive and be sensitive to change its electronic structure and its electronic properties under an external electric field. Through the Table 2, we can observe that the dipole moment $(\rho)$ of compounds D6 and D4 are greater than other dyes.

\section{Photovoltaic properties:-}

Generally for enhance the light harvesting efficiency of Dye sensitized solar cells; the choice of the appropriate donor and acceptor spacer are essential, so therefore, we calculated the frontier orbital energy gaps between HOMO and LUMO of six dyes (D1, D2, D3, D4, D5 and D6).

\section{Theoretical background:-}

The power conversion efficiency ( $\eta$ ) was calculated according to the Eq. 5:

$$
\eta=\frac{F F V_{o c} J_{s c}}{P_{i n c}}
$$


where $\mathrm{P}_{\text {inc }}$ is the incident power density, $\mathrm{J}_{\mathrm{sc}}$ is the short-circuit current, $\mathrm{V}_{\mathrm{oc}}$ is the open-circuit voltage, and FF denotes the fill factor. To analyze the relationship between $\mathrm{V}_{\mathrm{OC}}$ and $\mathrm{E}_{\mathrm{LUMO}}$ of the dyes based on electron injection (in DSSCs) from LUMO to the conduction band of semiconductor $\mathrm{TiO}_{2}\left(\mathrm{E}_{\mathrm{CB}}\right)$, the energy relationship can be expressed [38]:

$$
\mathrm{V}_{\mathrm{oc}}=\mathrm{E}_{\mathrm{LUMO}}-\mathrm{E}_{\mathrm{CB}}
$$

The obtained values Voc of the studied dyes calculated according to the Eq. 6 range from $1.0535 \mathrm{eV}$ to $1.4955 \mathrm{eV}$ of $\mathrm{TiO}_{2}$ (Tab. 3) these values are sufficient for a possible efficient electron injection.

The $\mathrm{J}_{\mathrm{SC}}$ in DSSCs is determined by the following equation [39]

$$
J_{s c}=\int L H E(\lambda) \Phi_{\text {inject }} \eta_{\text {collect }} d \lambda
$$

where $\operatorname{LHE}(\lambda)$ is the light harvesting efficiency at a given wavelength, $\Phi_{\text {inject }}$ evinces the electron injection efficiency, and $\eta_{\text {collect }}$ denotes the charge collection efficiency. In the systems which are only different in sensitizers, $\eta_{\text {collect }}$ can be reasonably assumed to be constant. LHE $(\lambda)$ can be calculated from the following equation

$$
L H E=1-10^{-f}
$$

where $f$ represents the oscillator strength of adsorbed dye molecules. $\Phi_{\text {inject }}$ is related to the driving force $\Delta \mathrm{G}_{\text {inject }}$ of electrons injecting from the excited states of dye molecules to the semiconductor substrate. It can be estimated as [40]

$$
\Delta G_{\text {inject }}=E_{O X}^{d y e^{*}}-E_{C B}^{\mathrm{TiO}_{2}}=E_{O X}^{d y e}+E_{0-0}^{d y e}-E_{C B}^{\mathrm{TiO}_{2}}
$$

From the equations 5-9, we could roughly predict the efficiency of novel dyes without intensive calculations. Where $E_{O X}^{d y e^{*}}$ is the oxidation potential of the excited dye, $E_{O X}^{d y e}$ is the redox potential of the ground state of the dye, $E_{0-0}^{d y e}$ is the vertical transition energy, and $E_{C B}^{T i O_{2}}$ is the conduction band edge of the $\mathrm{TiO}_{2}$ semiconductor. So $\mathrm{J}_{\mathrm{SC}}$ can be well estimated through $f$ and $\Delta \mathrm{G}_{\text {inject }}$. Two models can be used for the evaluation of $E_{O X}^{d y e^{*}}$ [41]. The first implies that the electron injection occurs from the un relaxed excited state. For this reaction path, the excited state oxidation potential can be extracted from the redox potential of the ground state, $E_{O X}^{d y e}$ which has been calculated at the B3LYP-6-31G(d) approach and the vertical transition energy corresponding to the photoinduced intermolecular CT (ICT),

$$
E_{O X}^{d y y^{*}}=E_{O X}^{d y e}-\lambda_{\max }^{I C T}
$$

where $\lambda_{\max }^{I C T}$ is the energy of the ICT. Note that this relation is only valid if the entropy change during the light absorption process can be neglected. For the second model, one assumes that electron injection occurs after relaxation. Given this condition, $E_{O X}^{d y e}$ is expressed as [42]:

$$
E_{O X}^{d y e^{*}}=E_{O X}^{d y e}-E_{0-0}^{d y e}
$$

\section{Electron injection:-}

The description of the electron transfer from a dye to a semiconductor, the rate of the charge transfer process can be derived from the general classical Marcus theory, [43-45].

$$
k_{\text {inject }}=\left|V_{R P}\right|\left(2 / h\left(\pi / \lambda k_{B} T\right) 1 / 2 \exp \left[-\left(\Delta G^{\text {inject }}+\lambda\right) 2 / 4 \lambda k_{B} T\right]\right.
$$

In eq. (12), $\mathrm{k}_{\text {inject }}$ is the rate constant (in s-1) of the electron injection from dye to $\mathrm{TiO} 2, \mathrm{kB}$ is the Boltzmann thermal energy, h the Planck constant, $\mathrm{G}^{\text {inject }}$ is the free energy of injection, $\left|V_{R P}\right|$ is the coupling constant between the reagent and the product potential curves. Eq (12) revealed that larger $\left|V_{R P}\right|$ leads to higher rate constant which would result better sensitizer. The use of the Generalized Mulliken-Hush formalism (GMH) allows evaluating |VRP| for a photoinduced charge transfer [43, 44]. Hsu et al. explained that |VRP| can be evaluated as [44] 


$$
\left|V_{R P}\right|=\frac{\Delta E_{R P}}{2}
$$

The injection driving force can be formally expressed within Koopmans approximation as

$$
\Delta E_{R P}=\left[E_{L U M O}^{d y e}+2 E_{H O M O}^{d y e}\right]-\left[E_{L U M O}^{d y e}+E_{H O M O}^{d y e}+E_{C B O}^{T i O_{2}}\right]
$$

where $E_{C B O}^{T_{C O}}$ is the conduction band edge. It is difficult to accurately determine $E_{C B O}^{T i O_{2}}$, because it is highly sensitive to the conditions (e.g. the $\mathrm{pH}$ of the solution) thus we have used $E_{C B O}^{\mathrm{TiO}_{2}}=-4.0 \mathrm{eV}$ [45] which is experimental value corresponding to conditions where the semiconductor is in contact with aqueous redox electrolytes of fixed $\mathrm{pH} 7.0$ $[46,47]$.

More quantitatively for a closed-shell system $E_{L U M O}^{d y e}$ corresponds to the reduction potential of the dye $E_{R E D}^{d y e}$, whereas the HOMO energy is related to the potential of first oxidation (i. e., $-E_{H O M O}^{d y e}=E_{O X}^{d y e}$ ). As a result, Eq. (11) becomes,

$$
\Delta E_{R P}=\left[E_{O X}^{d y e}+E_{O X}^{T i O_{2}}\right]
$$

The Photovoltaic properties $\lambda_{\max }, \Delta \mathrm{G}_{\text {inject }}, E_{O X}^{d y e}, E_{O X}^{d y *^{*}}, \lambda_{\max }^{I C T}$, and LHE, we have presented in Table 3. The short-circuit current $\left(\mathrm{J}_{\mathrm{sc}}\right)$ depends on two main influencing factors; light harvesting ability (LHE) and the electronic injection free energy $\left(\Delta \mathrm{G}_{\text {inject }}\right)$ (Eq. 7). The LHE is considered as a very important factor for the organic dyes in which we could appreciate the role of dyes in the DSSC, i.e. absorbing photons and injecting photo-excited electrons to the conduction band of the semi-conductor $\left(\mathrm{TiO}_{2}\right)$. In the order to know that to give an intuitional impression to how the influencing of donor spacer of the LHE, we simulated the UV/Vis absorption spectra of the six dyes. We remark that as the different dyes the oscillator strengths were changed. As shown in Table 3, the LHE of the dyes fall within the range: $0.2979-0.9303$. The LHE values for the dyes are in different ranges i.e that all the dyes will give different photocurrent.

The influencing factor as mentioned above, for enhancing the value of $\mathrm{J}_{\mathrm{sc}}$, which is the electronic injection free energy $\Delta \mathrm{G}_{\text {inject }}$. From the table 3 , for all studied dyes, $\Delta \mathrm{G}_{\text {inject }}$ is negative; this reveal that the electron injection process is spontaneous, and showing that dye's excited state would lies above the conduction band edge of $\mathrm{TiO}_{2}$ resulting favorable condition for electron injection. The calculated $\Delta \mathrm{G}_{\text {inject }}$ for these six dyes is decreased in the following order of D6>D2 $>\mathrm{D} 1>\mathrm{D} 3>\mathrm{D} 5>\mathrm{D} 4$. Among these six dyes, we observe that the dye D6 has the larger $\Delta \mathrm{G}_{\text {inject }}$, this maybe is due to the influencing of the extending the conjugate bonds. As a results, and based just from LHE and $\Delta \mathrm{G}_{\text {inject }}$ related to $\mathrm{J}_{\mathrm{sc}}$, we could conclude that the cell containing the dye D1, D2, D6 and D6 should have the highest $\mathbf{J}_{\mathrm{sc}}$ due to its relative large LHE and injection driving force compared to the dyes D3, D4 and D5.

Table 3:-The energy , $\Delta G^{\text {inject }}$, oxidation potential, light harvesting efficiency (LHE), $|V R P|$ and open-circuit voltage $\left(\mathrm{V}_{o c}\right)$ of investigated dyes at TD-B3LYP/6-31G(d) level of theory in gas phase

\begin{tabular}{|l|l|r|r|r|r|r|r|r|}
\hline dyes & Energy in a.u & \multicolumn{1}{|c|}{$E_{O X}^{\text {dye }}(\mathrm{ev})$} & \multicolumn{1}{|c|}{$E_{O X}^{\text {dyy* }}(\mathrm{ev})$} & \multicolumn{1}{|c|}{$\Delta G^{\text {inject }}(\mathrm{ev})$} & & $\left|V_{R P}\right|(\mathrm{ev})$ & $\mathrm{V}_{\text {oc }}(\mathrm{ev})$ & \multicolumn{1}{l|}{$\operatorname{IPCE}(\lambda)$} \\
\hline D1 & -1373.0784 & 5.8766 & 2.3655 & -1.6345 & 0.6107 & 0.9383 & 1.4081 & 0.9982 \\
\hline D2 & -1412.4023 & 5.8053 & 2.3622 & -1.6378 & 0.6927 & 0.9027 & 1.4955 & 1.1345 \\
\hline D3 & -1474.1925 & 5.9933 & 2.7578 & -1.2422 & 0.8401 & 0.9967 & 1.4160 & 1.0436 \\
\hline D4 & -1471.3668 & 6.1169 & 3.0674 & -0.9326 & 0.8826 & 1.0585 & 1.0535 & 0.8231 \\
\hline D5 & -1552.6171 & 5.8529 & 3.0056 & -0.9944 & 0.7053 & 0.9265 & 1.2165 & 0.7014 \\
\hline D6 & -1742.9756 & 5.1266 & 1.9591 & -2.0409 & 0.4964 & 0.5633 & 1.3752 & 1.0131 \\
\hline
\end{tabular}

\section{Absorption properties:-}

The absorption spectra of studied dyes have been computed at TD-DFT/BLYP with 6-31G (d) level of theory in gas phase. The excitation energies, absorption wavelengths, oscillator strengths and transition contribution are listed in Table 4 and Fig. 3. Electronic transitions up to 6 states were studied for all new designed sensitizers. According to the transition character, most of the dyes show the HOMO $\rightarrow$ LUMO transition as the first singlet excitation. The 
major contribution of the transition characters in in gas phase showing in table 4. The absorption wavelengths as shown in Table 4 and Figure 3, the absorption wavelengths of D1, D2, D3, D4, D5 and D6 in gas phase are 353.12, $360.09,383.20,406.57,435.45$ and 391.42 respectively.

Table4:-Calculated the $\lambda_{\max }(\mathrm{nm})$, excitation energies $\left(\mathrm{E}_{0-0}, \mathrm{eV}\right)$, oscillator strengths $(f)$, assignment of molecular orbital contributions and character of the studied compounds obtained by TD-DFT/B3LYP/6-31G(d) level in gas phase.

\begin{tabular}{|l|l|l|l|l|}
\hline dyes & $\lambda_{\max }$ & $\mathrm{E}_{0-0}$ & $f$ & assignments \\
\hline D1 & 353.12 & 3.5111 & 0.4097 & $\mathrm{H}-1 \rightarrow \mathrm{L}(87.23 \%) ; \mathrm{H} \rightarrow \mathrm{L}(11.16 \%)$ \\
\hline D2 & 360.09 & 3.4431 & 0.5123 & $\mathrm{H}-1 \rightarrow \mathrm{L}(81.90 \%) ; \mathrm{H} \rightarrow \mathrm{L}(16.57 \%)$ \\
\hline D3 & 383.20 & 3.2355 & 0.796 & $\mathrm{H} \rightarrow \mathrm{L}(97.70 \%)$ \\
\hline D4 & 406.57 & 3.0495 & 0.9303 & $\mathrm{H} \rightarrow \mathrm{L}(98.74 \%)$ \\
\hline D5 & 435.45 & 2.8473 & 0.5306 & $\mathrm{H} \rightarrow \mathrm{L}(97.96 \%)$ \\
\hline D6 & 391.42 & 3.1675 & 0.2979 & $\mathrm{H}-2 \rightarrow \mathrm{L}(93.74 \%) ; \mathrm{H} \rightarrow \mathrm{L}(2.96 \%)$ \\
\hline
\end{tabular}
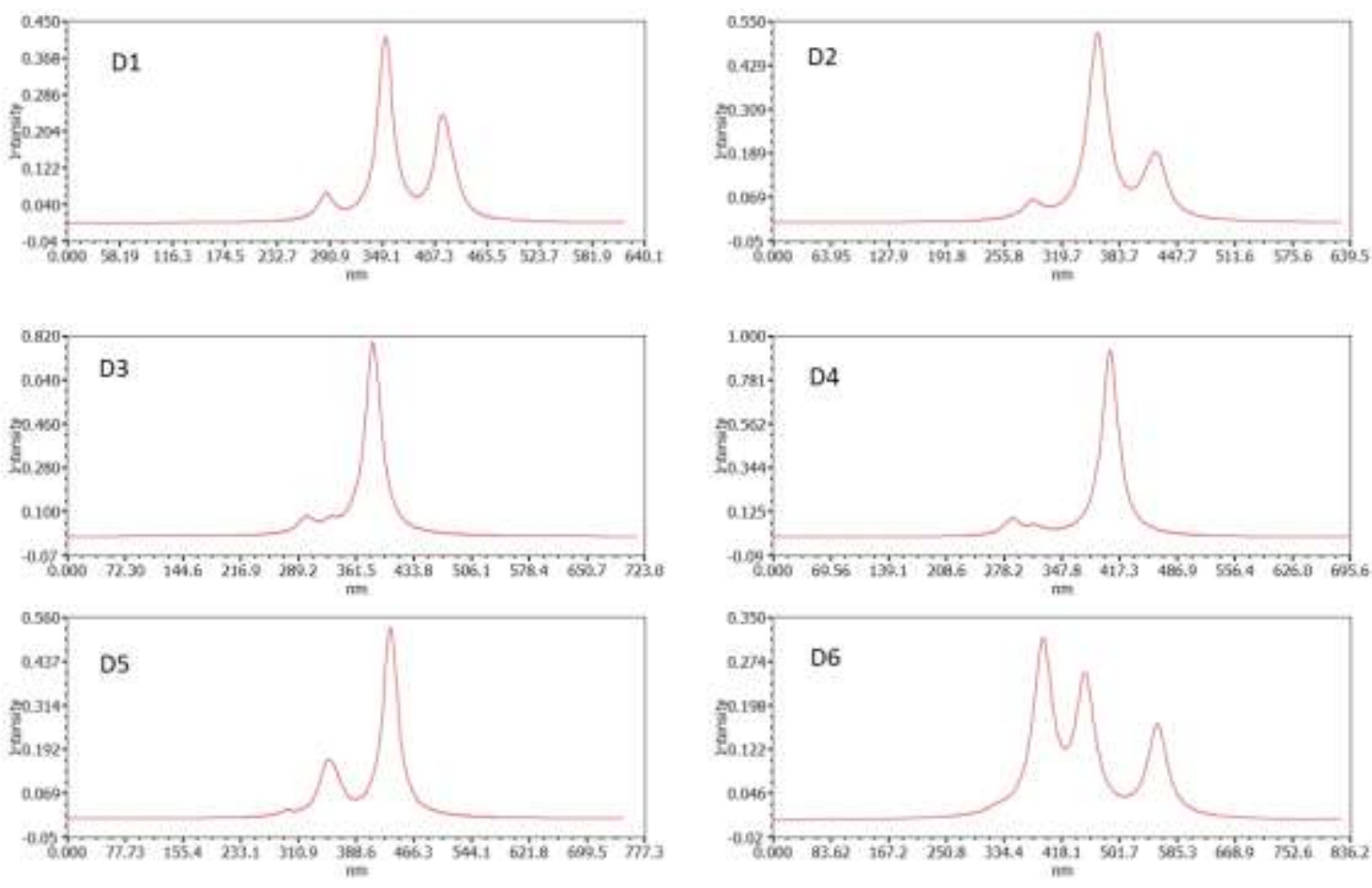

Figure 3:-The calculated UV absorption spectra of studied dyes in gas phase by TD-DFT/B3LYP with 6-31G (d) basis set.

\section{Conclusions:-}

In this study, we have used the DFT/B3LYP and DFT/B3LYP method with 6-31G(d) basis set to investigate theoretical analysis of the geometries, electronic properties, optical properties of new azo dyes. The modification of chemical structures can greatly modulate and improve the electronic and optical properties of studied dyes. The LUMO energy levels of all dyes are much higher than that of $\mathrm{TiO} 2$ conduction band edge, suggesting that the photoexcited electron transfer from $\mathrm{Di}$ to $\mathrm{TiO} 2$ may be sufficiently efficient to be useful in photovoltaic devices. The calculated $\Delta \mathrm{G}_{\text {inject }}$ for these six dyes is decreased in the following order of D6 $>\mathrm{D} 2>\mathrm{D} 1>\mathrm{D} 3>\mathrm{D} 5>\mathrm{D} 4$. Among these six dyes, we observe that the dye D6 has the larger $\Delta \mathrm{G}_{\text {inject }}$, this maybe is due to the influencing of the extending the conjugate bonds. In another hand, the D6 dye has a low value of chemical hardness ( $\eta$ ) in comparison with other dyes; this indicates that the D6 is very easy to liberate the electrons. The order of liberate of the electrons are D6> D5> D4> D1> D2 >D3. We could conclude that the cell containing the dye D1, D2, D6 and D6 should have the highest $\mathbf{J}_{\mathrm{sc}}$ due to its relative large LHE and injection driving force compared to the dyes D3, D4 and D5. 


\section{References:-}

1. Kohn W., Heeger A. The Power of the Sun. 2005. Available online: http:/powerofthesun.ucsb.edu

2. Kammen D.M. The rise of renewable energy. Sci. Am., 295 (2006) 84.

3. O’Regan B., Gratzel M., Nature., 353 (1991) 737.

4. Gratzel M., J. Photochem. Photobiol., C 4 (2003) 145.

5. Gratzel M., J. Photochem. Photobiol., A 164 (2004) 3.

6. Nazeeruddin M. K., Klein C., Liska P., Gratzel M. ., Coord. Chem. Rev., 249 (2005) 1460.

7. Mishra A., Fischer M.K.R., Bäuerle P., Angew Chem Int Ed Engl., 48 (2009) 2474.

8. Zhang ., Li H.B., Sun S.L., Geng Y., Wu Y., Su Z.M., J Mater Chem., 22 (2012) 568.

9. Fan W., Tan D., Deng W.Q., Chemphyschem., 13 (2012) 2051.

10. Gu X., Zhou L., Li Y., Sun Q., Jena P., Phys Lett A., 376 (2012) 2595.

11. Zhang J., Kan Y.H., Li H.B., Geng Y., Wu Y., Su Z.M.,Dyes Pigm., 95 (2012) 313.

12. Sanchez-de-Armas R., San Miguel M.A., Oviedo J., Sanz J.F., Phys Chem Chem Phys., 14 (2012)225.

13. Yang L., Guo L., Chen Q., Sun H., Liu J., Zhang X., Pan X., Dai S., J Mol Graph Model., 34 (2012)1.

14. Mohammadi N., Mahon P.J., Wang F., J Mol Graph Model, 40 (2013) 64.

15. Wang J., Gong S., Wen S.Z., Yan L.K., Su Z.M., J Phys Chem C., 117 (2013) 2245.

16. Feng J., Jiao Y., Ma W., Nazeeruddin M.K., Grätzel M., Meng S., J Phys Chem C., 117 (2013) 3772.

17. Kirkan B., Gup R., Turk. J. Chem., 32 (2008) 9.

18. SI Y., Hu Q., Huang Z., Yang G. and Yin J., Turk. J .Chem., 29 (2005) 135.

19. Maradiya H.R., Patel V.S.,J. Serb. Chem. Soc., 66 (2001) 87.

20. Sokolowska-Gajda J., Freeman H.S., Reife A., National Textile Annual Reports., 30 (1993) 167.

21. Maradiya H.R., Turk. J. Chem, 25 (2001) 441.

22. Ohashi A., Tsukuda T., Watara H., Anal. Sci., 19 (2003) 1085.

23. Karipcin F., Kabalcilar E., Acta. Chim. Slov., 54 (2007) 242.

24. Patel V.H., Petal M.P., Patel R.G., J. Serb. Chem. Soc., 67 (2002) 727.

25. Maradiya H.R., Patel V.S., J.Braz.Chem.Soc., 12 (2001) 1.

26. Kutgen H.K., Heren Z., Turk. J. Chem., 22 (1998) 403.

27. Frisch M.J., Trucks G.W., Schlegel H.B., Scuseria G.E. Robb, M.A. Cheeseman J.R., Scalmani

28. G.,Barone V., et.al.,Gaussian 09, Revision A.02, Gaussian, Inc., Wallingford CT, 2009

29. Ando S., Nishida J., Inohue Y., Tokito S., Yamashita Y., Idem. Synth. Met.,156 (2006) 327.

30. Shi Q., Fan H., Liu Y., Hu W., Li Y., Zhan X., J. Phys. Chem. C, 114 (2010) 16843.

31. Zhang M., Guo X., Li Y., Adv. Energy Mater., 1 (2011) 557.

32. Otutu J.O., IJRRAS., 15(2) (2013) 292.

33. Parr R..G, SzentpRly L..V., Liu S., J. Am. Chem. Soc., 1999 (1922) 121.

34. Chattaraj P,K,, Maiti B,, Sarkar U., J. Phys. Chem. A., 107 (2003) 4973.

35. Parr R.G., Yang W., Density Functional Theory of Atoms and Molecules; Oxford University Press: Oxford, $\mathrm{UK} ; 1989$.

36. Pauling L., The Nature of the Chemical Bond, 3rd ed., Cornell University Press, Ithaca, New York, 1960

37. Parr R.G., Pearson R.G.. J. Am. Chem. Soc., 105 (1983) 7512.

38. Marinado T., Nonomura K., Nissfolk J., Karlsson M. K., Hagberg D. P., Sun L., Mori S., Hagfeldt A., Langmuir., 26 (4) (2009) 2592.

39. Zhang J., Li H.B., Sun S.L., Geng Y., Wu Y., Su Z.M., J. Mater. Chem., 22(2) (2012) 568.

40. Katoh R., Furube A., Yoshihara T., Hara K., Fujihashi G., Takano S., Murata S., Arakawa H.,TachiyaJ. Phys. Chem. B., 108 (15) (2004) 4818.

41. Barbara P.F., Meyer T.J., Ratner M.A., J Phys Chem, 100 (1996) 13148.

42. De Angelis F., Fntacci S., Selloni A., Nanotechnology., 19 (2008) 424002.

43. Pourtois G., Beljonne J., Ratner M.A., Bredas J.L., J Am Chem Soc., 124 (2002) 4436.

44. Hsu C., Acc Chem Res., 42 (2009) 509.

45. Marcus R.A., Rev Mod Phys., 65 (1993) 599.

46. Asbury J.B., Wang Y.Q., Hao E., Ghosh H., Lian T., Res Chem Intermed, 27 (2001) 393.

47. Katoh R., Furube A., Yoshihara T., Hara K. et al., J Phys Chem B, 108 (2004) 4818.

48. Hagfeldt A., Grätzel M., Chem Rev, 95 (1995) 49.

49. Lukeš V., Aquino A., Lischka H., J Phys Chem A., 109(45) (2005) 10232. 